\title{
EL PASAJE COMO MODUS OPERANDI: PERSPECTIVAS SIMULTÁNEAS Y RECÍPROCAMENTE EXCLUYENTES EN LOS INGRÁVIDOS DE VALERIA LUISELLI
}

\author{
Maria Pape \\ University of Pennsylvania \\ mariapap@sas.upenn.edu
}

\section{RESUMEN / ABSTRACT}

El presente artículo realiza un estudio del pasaje como tema y procedimiento clave en Los ingrávidos de Valeria Luiselli -obra reclamada por la crítica pero poco trabajada. La novela se deja leer a partir de este motivo, que se reitera al nivel de la forma, de la trama y de su afiliación poética. Esta última cuestión se abordará a través de una doble lectura de la obra, primero, en relación con la literatura fantástica latinoamericana y, luego, en relación con el hiperrealismo norteamericano de las artes plásticas. Por último, proponiendo un marco de comprensión para Los ingrávidos, relacionamos la obra con las reflexiones de Nicolas Bourriaud acerca del arte contemporáneo radicante. Así, se alumbrarán tanto la constitución de un espacio narrado como de un territorio cultural luiselliano.

PALABRAS Clave: Valeria Luiselli, Los ingrávidos, hiperrealismo, literatura fantástica, radicante.

This article explores passages as a key motif and organizing structure in Valería Luiselli's Los ingrávidos, a work praised by the critics, but so far, neglected by the scholars. The novel lends itself to a reading that focuses on this theme tracing its reiteration at the level of form, plot, and aesthetical affiliation. The latter element is addressed through a twofold analysis of relation to Latin American fantastic literature and to North American hyperrealism in the visual arts. Finally, by relating Los ingrávidos to Nicolas Bourriaud's ideas on the radicant contemporary art, the article situates the novel within a broader context, which permits an appreciation for the constitution of Luiselli's narrated space and her cultural territory.

KEY WORDS: Valeria Luiselli, Los ingrávidos, Hyperrealism, fantastic literature, radicante. 
After all, people are not born on this earth as plants, but rather as travellers. Both history and holy scripture teach us that all of creation is in fact a community of travellers. - Ibrahim al-Koni cit. en Fähndrich

[U]na vez más no voy a ordenar el librero. Lo que me falta es un criterio: ¿Borges va después de Arlt, Poe, Stevenson o las Las mil y una noches? ¿Pertenecen Shakespeare y Dante a la misma estantería? Es difícil saber cuánto peso vierte el título de un libro sobre el siguiente. - Luiselli, Papeles falsos

El epígrafe de Papeles falsos (2010) exhibe la operación principal de la obra de Valeria Luiselli: la creación del espacio -tanto del mundo narrado como del mundo literario. El trabajo comienza ya en el primer ensayo de Papeles falsos y continua en las novelas Los ingrávidos (2011) y La historia de mis dientes (2013) como la inclinación de la mano que escribe. Un primer acercamiento a la escritura luiselliana -elogiada tanto y trabajada tan pocoes el objetivo de este texto.

En las siguiente páginas propondremos una lectura de Los ingrávidos a partir del pasaje. Desarrollaremos la función del pasaje investigando, en primer lugar, cómo se expresa en la forma, en segundo lugar, cómo se expresa temáticamente en el movimiento entre los dos narradores intradiegéticos -la narradora y Owen ${ }^{1}$. Nos enfocaremos en esta última manifestación del pasaje y argumentaremos que se deja comprender desde perspectivas distintas realizando una lectura desde la literatura fantástica y desde el hiperrealismo. Por último, propondremos que este uso de procedimientos de varias tradiciones literarias y artísticas en la construcción de la interconexión entre la narradora y Owen resulta en un pasaje entre ellas. Al investigar estas relaciones, volveremos a la invitación implícita del epígrafe preguntándonos: ¿dónde colocar a Valeria Luiselli en el librero? Sugeriremos las reflexiones de Nicolas Bourriaud

1 La novela tiene tres narradores: un narrador extradiegético omnisciente más Owen y la mujer mexicana que son narradores homodiegéticos e intradiegéticos, dado que son personajes tanto en el relato del narrador extradiegético como en sus propias narraciones. Para no causar confusión durante el artículo entre Owen y el narrador extradiegético, llamaremos a Owen por su nombre y reservaremos el título el narrador para el narrador extradiegético. 
acerca del arte radicante como un marco de comprensión preliminar que nos deja ver este unión de procedimientos de varias tradiciones como una marca característica del arte y la literatura contemporáneos.

\section{EL METRO}

En Los ingrávidos, el juego con lo espacio-temporal es la piedra angular de la ficción. La novela se construye como el vaivén de fragmentos entre dos líneas narrativas distintas, pero relacionadas entre sí. En México, una mujer mexicana vive con su hijo, su bebé y su marido. Ella, en sus breves ratos libres, escribe acerca de su presente en su país de origen, su pasado en Nueva York y lo que parece ser el fantasma del poeta mexicano, Gilberto Owen, a quien solía ver en el metro. En Filadelfia, al borde de su muerte, Gilberto Owen escribe acerca de su juventud durante el Renacimiento de Harlem, su presente como enfermo y divorciado y una novela narrada en primera persona por "una mujer de rostro moreno y ojeras hondas que tal vez se haya muerto" (Luiselli, Los ingrávidos 112) y que se parece mucho a la mujer mexicana.

Temáticamente, las descripciones largas de recorridos y viajes no dominan la novela. De hecho, la narradora escribe que en su juventud en Nueva York "paseaba poco, en la ciudad donde todo el mudo pasea" (Ibíd. 24) y que sus únicas caminatas en el presente, como madre en México, "son entre la cocina y la sala, entre el baño de arriba y el cuarto del mediano y la bebé" (Ibíd. 25). Con casi las mismas palabras, Owen comenta que en su juventud en Nueva York también "paseaba poco, en esa ciudad donde todo el mundo pasea" (Ibíd. 116).

Sin embargo, detrás de esta aparente inmovilidad se articula la movilidad. En el salto fragmento a fragmento, la novela misma se mueve cambiando de escenario. El lector pasa constantemente de un edificio a otro, de una ciudad a otra e incluso de un país a otro. Estos saltos son acompañados por el cambio perpetuo entre las voces de Owen y la narradora, lo que constituye otro nivel de movimiento. De este modo, la movilidad funciona como una condición fundamental para la construcción de Los ingrávidos ${ }^{2}$. Solo que en vez de tomar al viaje como imagen, la movilidad parece tomar la forma 
del pasaje, dada la falta de interés por la trayectoria y el énfasis en un pase más directo entre lugares.

Si nos detenemos en el metro, que funciona como una imagen clave de la obra, la figura del pasaje se explicita ${ }^{3}$. Según una de las notas de la narradora, Owen dice que "[a] Nueva York se la empieza a ver desde el subway. Acaba allí la perspectiva plana, horizontal. Empieza un paisaje de bulto ahí, con la doble profundidad, o eso que llaman cuarta dimensión, del tiempo" (Ibíd. 44). Ver la ciudad desde el metro equivale a un cambio de perspectiva: desde la profundidad no se ve la tierra como una extensión continua en perspectiva plana, sino como un conjunto de puntos geográficos distribuidos por una red de tubos oscuros. En un vagón del metro la distancia y la dirección se convierten en parámetros abstractos para el pasajero común, que no tiene manera de medir ninguna de las dos. Así, más que acentuar la idea del viaje, el metro transmite la idea del pasaje.

Durante el libro esta cita se repite y se transforma en comentarios breves, volviéndose un modelo para la forma de la novela: "Una novela vertical, contada horizontalmente. Una historia que se tiene que ver desde abajo, como Manhattan desde el subway" (Ibíd. 126). Al leer la novela como se ve Manhattan desde el metro, cada fragmento se convierte en una estación y cada blanco en una parte de la red de tubos que las conecta. La idea del pasaje se extiende del pasaje que sienten los personajes con el cambio de estación al que siente el lector con el cambio de escenario ficcional al pasar de un fragmento a otro. Por lo tanto, como uno en el metro puede bajar en la estación que quiera, con esta imagen de la estructura Los ingrávidos invita al lector a hacer lo mismo con sus fragmentos ${ }^{4}$. Es decir, la novela se convierte en un mapa esperando que el lector trace y retrace sus propios recorridos ${ }^{5}$.

\footnotetext{
El subway de Nueva York no va siempre por debajo de la tierra, pero la novela se enfoca solamente en esta parte.

$4 \quad$ Si bien la novela no se estructura cronológicamente, parece haber una lógica narrativa progresiva que culmina en el colapso narrativo del final-que trataremos más adelante. Esta lógica va en contra de la idea de la novela como un mapa dado que presupone un cierto desarrollo.

Esta es una operación similar a la que vemos en Papeles falsos. "La habitación y media de Joseph Brodsky”, por ejemplo, se estructura por los hoteles, cuyos nombres forman los encabezamientos. En "Mancha de agua" el procedimiento se repite con ríos y en "Dos calles y una banqueta” con calles de México D.F. De este modo, Luiselli invita al lector a pensar los textos como territorios para recorrer. Asimismo, la íntima relación entre el texto y el espacio físico sobresale en La historia de mis dientes. Por ejemplo, al final de la novela,
} 


\section{II. ¿UN ENCUENTRO?}

Para desarrollar mejor la idea del pasaje conviene referirnos a Walter Benjamin quien le ha dedicado gran atención en su Libro de los pasajes (1927-1940). Los pasajes parisinos, que cubren la calle con un techo característico de vidrio y metal, son, para él, una especie de lugares dobles que borran la distinción clara entre afuera y adentro. Funcionan como los salones de los burgueses (Benjamin M3a,4). Acentuando la particularidad de este espacio, Benjamin conecta los pasajes con lo onírico atribuyéndoles una cierta flexibilidad espacial: "Todo el mundo conoce en los sueños el miedo a las puertas que no cierran [...] El camino que hacemos a través de los pasajes también es en el fondo un camino de fantasmas en el que las puertas ceden y las paredes se abren" (Ibíd. L2,7). Sin embargo, esa flexibilidad no está limitada a lo espacial sino que también se extiende a lo temporal: "son las galerías que conducen a su pasada existencia” (Ibíd. C1a,2). Ya en el momento de Benjamin, los pasajes parisinos, antes tan espléndidos y llenos de luz, se habían vuelto obsoletos convirtiéndose en signos del pasado. En ellos el pasado y el presente conviven posibilitando el pasaje a un momento anterior. Así, el pasaje es tanto un lugar físico como la ruptura de los límites de éste en cuanto a tiempo y espacio.

El metro de Los ingrávidos, como ahora vamos a ver, guarda alguna relación a los pasajes de Benjamin por cuanto es un espacio dotado con la flexibilidad espacial y temporal ${ }^{6}$. El metro es un escenario del pase momentáneo -o más bien el pase posible dado que su existencia nunca se establece con seguridad- entre el mundo de la narradora y el mundo de Gilberto Owen.

Roberto Bálser escribe la historia de los últimos meses de la vida del hombre llamado Carretera; un texto que es, a la vez, el primer esbozo de lo que "será el Tour Carretera -el primer tour del gran relingo de Ecatepec” (Luiselli, La historia de mis dientes 107). Acompañado por una serie de fotos de los sitios mencionados compilados al final del libro, el texto se convierte en una especie de guía turística alternativa que invita al lector a intentar realizar el recorrido de Ecatepec, un barrio fuera de México D.F., tanto en las calles como las páginas.

6 Es pertinente comentar que Benjamin, de hecho, relaciona el pasaje y el metro. "Hay otro sistema de galerías que recorre París bajo tierra: el metro, donde al atardecer brillan unas luces que señalan el camino al Hades de los nombres. Combat - Elysée - Georges V Etienne Marcel- Solférino - Invalides - Vangirard se han arrancado las ignominiosas cadenas de calle o plaza para convertirse aquí, en una oscuridad atravesada de relámpagos y pitidos, en deforme dioses de las alcantarillas, en hadas de las catacumbas" (Ibíd. C1a,2). Así, el metro parece el mellizo negro y enloquecido del pasaje. Sin embargo, el metro de Luiselli no se puede comprender desde esta perspectiva sino más bien en relación con las gallerías parisinas. 
En total, la narradora ve a Owen tres veces (Luiselli, Los ingrávidos 44, 64 y 78), pero la segunda es la más destacada. Ella está en el metro cuando de repente otro tren se acerca por detrás y, por un momento breve, va a la misma velocidad que el suyo.

Lo vi sentado, en la misma posición que yo había adoptado, con la cabeza reclinada sobre la ventana del vagón. [...] Cuando otra vez hubo oscuridad detrás de la ventana vi contra el vidrio mi propia imagen difusa. Pero no era mi rostro; era mi rostro superpuesto al de él -como si su reflejo se hubiera quedado plasmado en el vidrio $\mathrm{y}$ ahora yo me reflejara dentro de ese doble atrapado en la ventana de mi vagón. (Ibíd. 64)

La superposición imposible del reflejo de la mujer mexicana con el de Owen manifiesta una coexistencia de los mundos que en el tercer encuentro se desarrolla en una interacción cuando ella cree que Owen la saluda.

Owen también parece ver a la narradora, "sobre todo en esos momentos en que dos trenes andan por vías paralelas a la misma velocidad durante unos instantes" (Ibíd. 91). En un momento parecido: "La cabeza apoyada contra la ventana, estaba la mujer, con un sombrero de tela verde oliva y un abrigo rojo, abotonado hasta el cuello. Iba leyendo un libro de tapa blanca [... ] alcancé a leer el título que para mi sorpresa era una palabra en español 'Obras', decía" (Ibíd. 110). Ni el lector ni Owen saben si la mujer realmente es ella, pero es parecida -siendo mexicana quizás sea morena, lleva un abrigo rojo (Ibíd. 12) y lee un libro con el título Obras (Ibíd. 30). De esta manera se indica que hay un pasaje entre los dos mundos o más bien entre los dos tiempos; uno que no solo permite una coexistencia pasiva de ellos, sino también una interacción entre ellos ${ }^{7}$.

$7 \quad$ Este tipo de cruce no solo transcurre en el metro. Otro caso trata de una maceta con un naranjo que "parece una lámpara [y tiene ...] redondas llamas verdes" (Ibíd. 30). Gilberto Owen la tenía cuando vivía en Nueva York en los años 1928-1929 y después la abandonó en la azotea porque se le murió (Ibíd. 110). Aproximadamente 80 años más tarde, la narradora encuentra una maceta que "parecía una lámpara" (Ibíd. 32) con una planta que tal vez es un pequeño árbol seco en la azotea del viejo edificio de Owen y se la lleva. Sin embargo, solo unos meses después del primer incidente, Owen se da cuenta de que la maceta ya no está ahí (Ibíd. 122). Al final, cuando la narradora se muda de Nueva York deja la maceta en Filadelfia con su hermana (Ibíd. 81) y páginas después -pero años antes- Owen la reencuentra allí, en Filadelfia (Ibíd. 112). 
Los momentos de un aparente pasaje se dejan comprender de varias maneras. Aquí desarrollaremos dos: primero, una vista a la luz del género fantástico como resultado de una coexistencia de mundos; y, segundo, otra vista en la perspectiva del hiperrealismo como un juego entre la realidad y el arte.

\section{EL PASAJE FANTÁSTICO}

Antes de investigar la relación entre el pasaje y lo fantástico, primero es pertinente ceñir el género en términos más generales. En el prefacio de Antología del cuento fantástico (1958), Roger Caillois propone que se caracteriza por una intervención sobrenatural en el mundo real que culmina en terror. La condición necesaria de tal definición es la existencia de dos órdenes: un orden realista que gobierna un mundo real y perfectamente conocido para el lector y un orden sobrenatural, que Caillois no describe muy claramente, pero cuyas leyes son incompatibles con las del mundo real y por eso las desacreditan.

Otra definición clásica es la que hace Tzvetan Todorov en Introducción a la literatura fantástica (1970). Como punto de partida también toma la existencia de dos órdenes, pero desliza el enfoque. Primero, explica que el acontecimiento sobrenatural da lugar a dos explicaciones entre sí excluyentes -una provista por el orden sobrenatural y otra provista por el mundo familiar. Segundo, propone que es en la vacilación entre ellas que consiste lo fantástico; una vacilación que debe surgir en la percepción del lector. Entonces, lo fantástico se define principalmente por la ambigüedad.

En Los ingrávidos, lo fantástico surge justamente de la alta ambigüedad producida por el quiebre de un orden familiar en relación con lo espacial. Sin embargo, para ilustrar su índole particular es preciso verlo en yuxtaposición con las formas que lo fantástico ha tomado antes -por ejemplo, en la obra de Julio Cortázar, conocido por su fantástico espacial. Que la obra del escritor argentino puede ser relevante para la comprensión de Los ingrávidos lo señala la novela misma. En la azotea de Owen, la narradora se tiende "boca arriba" (Ibíd. 33) para pasar la noche. El momento tiene un fuerte aire fantástico por la frecuente mención de fantasmas y por el pasaje entre mundos que el hallazgo de la maceta, que acaba de hacer la narradora, indica. De este modo, la escena parece la realización del título del cuento "La noche boca arriba" de Final del juego (1956) y un saludo cordial a su escritor. 
En un homenaje que hace Beatriz Sarlo a Cortázar, ella propone el uso del espacio como clave en la obra y plantea -especificando- que la ficción cortazariana se caracteriza por mostrar "las consecuencias del pasaje entre espacios que la percepción normalizada mantiene escindidos" (18). Según Sarlo, el pasaje es central para toda la ficción del escritor argentino, pero no menos para sus cuentos fantásticos. José Amícola, por su parte, plantea que la cinta de Moebius es una representación icónica para la comprensión de lo fantástico cortazariano. La cinta pone "en escena no la nitidez de las fronteras, sino, por el contrario, la peligrosa fusión de bordes de territorios no reflejados de modo especular, sino presentados directamente contrapuestos" (Amícola 461). Visto así la cinta es una figura evidente del pasaje. Un pasaje sin rupturas, donde uno puede pasar de un lado a otro. Con esa imagen, Amícola acentúa la paradoja innata de estos pasajes, subrayando la fusión de contrapuestos.

Para ejemplificar estas observaciones tomaremos, continuando con las indicaciones de la novela de Luiselli, "La noche boca arriba". El cuento trata sobre un motociclista que después de tener un accidente vacila entre dos mundos; un mundo del siglo XX y otro de la América azteca. Quizá más acertado sería decir entre dos momentos históricos: la modernidad y la época precolombina, dado que el lector no sabe bien dónde transcurre el primero geográficamente. Al principio, el motociclista cree que el mundo azteca es solo un sueño, aunque "como sueño era curioso porque estaba lleno de olores y él nunca soñaba olores” (Cortázar, Final del juego 171). Luego se indica que puede ser causado por la fiebre, y al final, después de varias vacilaciones entre los dos mundos, el motociclista se queda en el mundo azteca y afirma "que el sueño maravilloso había sido el otro" (Ibíd. 179). Pero esto también se pone en duda, porque la ciudad del siglo XX, en la cual el motociclista al comienzo se manejaba con facilidad, de repente parece extrañada en los ojos del moteca. Si la última hipótesis del moteca es real y el mundo del siglo XX solo fue un sueño, si fue al revés o si realmente hay un pasaje entre los dos mundos, como el cuento discretamente propone, el lector no lo sabrá nunca.

En la definición de Todorov, lo fantástico se articula en la vacilación inevitable del lector y la consecuente ambigüedad. Sin embargo, con la caracterización de Caillois en mente, lo fantástico parece surgir del pasaje. Es cierto que hay elementos en los dos mundos que aterrorizan al lector inmediatamente con su brutalidad: el accidente en el siglo XX y las guerras floridas en la época precolombina. No obstante, aunque es más sutil el terror que produce el pasaje rompiendo con el orden familiar, es tal vez el más profundo. No solo propone la posible coexistencia de mundos, lo cual no 
es posible según la concepción tradicional del espacio -que permite solo un mundo- y del tiempo -que permite solo la progresión cronológica-, sino también propone la conexión entre ellos. Aun así, es preciso matizar la representación de la ruptura.

"La noche boca arriba” opera con un fuerte sentido de oposición entre dos mundos: por un lado, la modernidad, la civilización y la ciudad; por el otro, el pasado lejano, la barbarie de la guerra y la naturaleza. Pero aun antes del accidente vemos cómo la contraposición se suaviza sutilmente. La naturaleza entra de a poco en la ciudad cuando el protagonista llega a una calle que está "bordeada de árboles” donde "los jardines [llegan] hasta las aceras, apenas demarcadas por setos bajos" (Ibíd. 169). Sigue en el hospital cuando llevan al motociclista "hasta un pabellón del fondo, paseando bajo árboles llenos de pájaros" (Ibíd. 171). Del mismo modo, la ciudad entra en la naturaleza cuando, por primera vez en el mundo azteca, el protagonista vuelve en sí y se encuentra en una calzada que parece un eco de la calle del siglo XX. En vez de que una realidad irrumpa en la otra, cada una parece estirarse dejando a la otra entrar. Son opuestas, pero están íntimamente conectadas -como los dos lados de una cinta de Moebius. Visto así, el cuento se mueve en la tensión entre la ruptura y el estiramiento ${ }^{8}$.

Antes de continuar, es pertinente también introducir “Lejana” de Bestiario (1951) que nos va a permitir captar otra dimensión del pasaje fantástico en la obra de Luiselli. El cuento empieza con el diario de Alina Reyes de Aráoz, una joven porteña de la clase media alta, que se siente invadida por las experiencias de una mendiga de Budapest quien Alina cree es ella misma. Generalmente no duda de su vivencia pero a veces se apela a otras explicaciones como un sueño (Cortázar, Bestiario 33), un juego de pensamiento (Ibíd. 35) o la locura (Ibíd. 33). El lector no sabe qué pensar. Mientras el cuento está narrado en primera persona ninguna información puede ser tomada por cierta

$8 \quad$ En "Del sentimiento de lo fantástico" (1967), Cortázar propone que "lo fantástico fuerza una costra aparencial, y por eso recuerda al punto vélico" (Cortázar, La vuelta al día 74 , negritas originales). La primera parte de esa caracterización subraya, de acuerdo con Caillois a quien Cortázar se refiere, la idea de la ruptura, pero la segunda parte con la imagen de la vela transforma esta idea. El punto vélico es una referencia a una cita de Victor Hugo que lo define como un "lugar de convergencia, punto de intersección misterioso hasta para el constructor del barco, en el que se suman las fuerzas dispersas en todo el velamen desplegado" (Ibíd. 74). Entonces más que una ruptura, lo fantástico es una fuerza que mueve la realidad como el viento mueve un barco; o estira la realidad como el viento desdobla una vela. 
automáticamente. Sin embargo, cuando Alina y su marido viajan a Budapest, el diario termina y un narrador extradiegético retoma la narración. Este relata cómo Alina encuentra a la mendiga en medio de un puente. Se abrazan y "en la fusión total" (Ibíd. 39) la consciencia de la protagonista junto con la perspectiva del narrador pasan al cuerpo de la mendiga. Ahora ella es la mal vestida que, aterrorizada, ve a Alina Reyes alejándose. ¿Es una expresión de la locura máxima? ¿Cambiaron las conciencias de cuerpo a cuerpo? En la escena definitiva, el narrador extradiegético se liga tanto a la perspectiva de Alina que lo narrado puede corresponder tanto al mundo objetivo como al mundo interno de la protagonista enloquecida. Así, lo fantástico en "Lejana" en gran medida sigue la forma que vimos en "La noche boca arriba", en el cual el lector vacila entre varias explicaciones de órdenes distintos y el terror más profundo surge del pasaje. Solo que en "Lejana” el pasaje espacial se extiende a un pasaje entre identidades, manifestando el íntimo vínculo entre lo espacial y el motivo del doble.

\section{EL PASAJE EN LOS INGRÁVIDOS I}

En Los ingrávidos abundan marcas que tradicionalmente son indicadores de lo fantástico. Por ejemplo, tanto la narradora como Owen dicen que están escribiendo acerca de fantasmas: ella, "sobre el fantasma de Gilberto Owen" (Luiselli, Los ingrávidos 62) y él, sobre "una mujer de rosto moreno y ojeras hondas que tal vez se haya muerto" (Ibíd. 112). Como un presagio, el hijo de la narradora hace un dibujo de su casa derrumbada solo pocas páginas antes de que se derrumbe. Y Owen pierde peso sin perder volumen. No obstante, al mismo tiempo la novela rompe con las normas de este género deliberadamente. Por ejemplo, discordante con la definición de Caillois que ubica el terror en el centro de lo fantástico, la novela de fantasmas que escribe la narradora no da miedo, sino solo "un poco de tristeza" (Ibíd. 22). El epígrafe mismo señala la relación ambivalente con la advertencia: “¡Ten cuidado! Si juegas al fantasma, en uno te conviertes" (Ibíd. 9). Por lo tanto, la relación que la novela tiene con lo fantástico es de juego y no de filiación?.

\footnotetext{
En una entrevista, Luiselli declara que su novela no fue pensada como una novela fantástica y que se indignaría si alguien se lo plantease. En cambio, proclama que es una novela
} 
Como en los cuentos de Cortázar, en Los ingrávidos el pasaje es un elemento fantástico fundamental. La narradora y Owen parecen generalmente vivir en un mundo reconocible, a pesar de los fenómenos inexplicables, y el pasaje rompe con las leyes de ese orden familiar, demostrando: primero, la coexistencia de diferentes momentos históricos en un mismo lugar geográfico; y, segundo, la posibilidad de comunicación e interacción entre ellos. Fundamentalmente, es una manifestación de la reconfiguración de los conceptos espacio y tiempo.

Owen declara que escribir novelas es tratar "de congelar el tiempo, sin detener el movimiento de las cosas” (Luiselli, Los ingrávidos 116). Esta idea casi solo se deja comprender en la luz de las reflexiones más extensas acerca del mapa de Papeles Falsos. En "Mancha de agua”, Luiselli propone: "Un mapa es una abstracción espacial; imponerle una dimensión temporal [...] contradice su propósito mismo [...] Necesitamos del plano abstracto, de la bondad de las dos dimensiones, para deslizarnos a nuestra conveniencia, para tejer y destejer recorridos posibles, planificar itinerarios, desdibujar rutas" (Luiselli, Papeles falsos 25). Es decir, el tiempo impide trazar recorridos alternativos o volver atrás y con eso nos limita. En cambio, las dos dimensiones del espacio posibilitan una pluralidad de recorridos simultáneos porque rutas distintas pueden coexistir. En Los ingrávidos, la reconfiguración de espacio y tiempo se manifiesta como la ampliación del espacio que se estira hasta abrazar momentos históricos distintos y dejar que la narradora y Owen se encuentren. Luiselli espacializa el tiempo convirtiéndolo en un territorio recorrible como el espacio representado en un mapa ${ }^{10}$.

El pasaje espaciotemporal se profundiza en la relación entre la mujer mexicana y Owen como un pasaje entre identidades. La novela se construye como un juego del doble -otro tema clásico de Cortázar como del género fantásticoentre los dos protagonistas. En 1928-1929, Owen vive en Morningside Av. 63,

hiperrealista (cit. en Barbosa Vera y Scofaulos). Sin embargo, la obra misma se presta a ambas lecturas -una en relación con lo fantástico y otra en relación con la corriente hiperrealista.

10 Según Luiselli, la inspiración para este reconfiguración viene de Juan Rulfo, quien amplió el espacio y quebró la estructura temporal de la narrativa creando una gran libertad para otros (cit. en Reynolds). Incluir a Rulfo en un texto que se ocupa de lo fantástico, exige un comentario. Cuando Luiselli menciona a Rulfo no lo hace refiriéndose al realismo mágico, sino solo a la ruptura con la estructura temporal que puede ser tanto un rasgo del realismo mágico como de la literatura fantástica. Eso dicho, las múltiples fuentes de Los ingrávidos indican que una lectura en relación con Rulfo o el realismo mágico sería posible y rica. Solo que excede los límites del artículo presente. 
Nueva York, muy cerca de donde la narradora vivirá aproximadamente 80 años más tarde. Los dos son mexicanos, escritores y tal vez fantasmas o por lo menos parecen afantasmarse mientras cada uno escribe una novela acerca del otro. Además, hay varias referencias al motivo del doble. La segunda vez que la narradora ve a Owen, su reflejo se superpone al de él, su "doble atrapado en la ventana de [su] vagón” (Luiselli, Los ingrávidos 64, cursivas añadidas). Otra vez, en un homenaje a artistas mexicanos, ella directamente se introduce como Owen (Ibíd. 75).

El juego del doble también se repite en la forma de la novela. La narradora comienza la narración reflexionando acerca de sus dificultades de escribir y comenta que le hubiera gustado "empezar como termina A Moveable Feast de Hemingway" (Ibíd. 11). Casi llegando a la mitad, todo parece comenzar de vuelta, solo que ahora con Owen como el narrador. También comienza su escritura reflexionando acerca de sus dificultades para escribir y comenta que le hubiera gustado "empezar como empieza The Crack-Up de Fitzgerald" (Ibíd. 63), otro libro del canon norteamericano que también se publicó post mortem. Al final, esta construcción paralela se desestabiliza y colapsa cuando los mundos distintos -representados por varios personajes- empiezan a coincidir en el departamento de Owen. Primero, aparecen personajes de la época de Owen como Ezra Pound, Federico García Lorca y William Carlos William. Luego, la narradora y sus hijos también ingresan de a poco en el departamento de Owen. Al principio, como "unas voces" (Ibíd. 142), y al final, como personajes físicamente presentes. En el último fragmento, Owen cuenta: "En la oscuridad blanca, escucho a mi lado la risa suave, ráfaga alegre, de un bebé. Siento elevarse la sábana que me cubre, el calor del cuarto entrar y sacudirme el cuerpo, la voz excitada de un niño golpearme la cara:/ ¡Encontrado!” (Ibíd. 143). Durante la novela, el hijo y la narradora juegan a las escondidas en varias ocasiones, pero aquí Owen se convierte en parte del juego y queda en suspenso si solo es la culminación de la superposición de los momentos históricos y geográficos o si, además, es la culminación del motivo del doble. ¿La narradora y Owen intercambian partes o terminan siendo uno mismo? De esta manera, el juego del doble también es un pasaje: un pasaje identitario cuya realización termina en un colapso narrativo ${ }^{11}$.

11 Lo mismo pasa con la estructura: lo que al comienzo eran fragmentos de tamaño variado que se conectaban por las historias de los personajes, alusiones y citas, al final se vuelven fragmentos de apenas unas líneas que casi se desconectan y a veces se reducen a 
El paralelo entre el pasaje como elemento fantástico de Los ingrávidos y el pasaje fantástico de los cuentos de Cortázar es claro: en los dos casos lo fantástico surge fundamentalmente de lo espacial. Pero mientras lo fantástico cortazariano surge de la multiplicación de momentos históricos en distintos lugares geográficos marcados por la oposición entre ellos, lo fantástico de Luiselli nace de la multiplicación de momentos históricos en un mismo lugar geográfico. Mientras en Cortázar una realidad se estira abrazando a otra, en Luiselli la realidad misma se estira transformando sus propias leyes. Mientras la interconexión de los personajes en Cortázar termina en la constitución de una unidad identitaria nueva -una mente en un cuerpo- en Luiselli ese cambio parece suspenderse en el estado de fusión, coincidiendo con o directamente generando el colapso narrativo.

Volviendo a la definición de lo fantástico de Todorov, vemos que el pasaje resulta en una ambivalencia. Generalmente, los personajes parecen convencidos de la existencia de los acontecimientos fantásticos, pero a veces la duda se manifiesta en pequeñas marcas de inseguridad como le parece a la narradora que vio a Owen o que cree que la saludó (Ibíd. 43 y 78). En definitiva, el que más dudas acaba teniendo es el lector. ¿Cómo puede ser que en un mundo reconocible sea posible pasar de un momento histórico a otro? Considerar el efecto fantástico como una vacilación entre dos explicaciones provistas por dos órdenes - uno familiar y otro fantástico- no parece hacer justicia a la complejidad de Los ingrávidos. En cambio, la ambivalencia parece venir de la vacilación entre dos explicaciones plausibles, pero incompatibles y coexistentes. Como mencionamos antes, la narradora escribe una novela acerca de Owen y Owen una acerca de ella, con lo cual la realidad de uno puede ser nada más que la ficción del otro y así la distinción entre realidad y ficción se disuelve. Ya no se trata de creer o no creer en la existencia de los hechos fantásticos, sino de la misma realidad de la narración. El lector se ve forzado a abandonar su "willing suspension of disbelief" (Coleridge 6).

citas sueltas o fuera de contexto. Tomaremos como ejemplo el penúltimo fragmento: "No, son las moscas del verano. Y los mosquitos. De día están en la regadera y de noche nos pican” (Luiselli, Los ingrávidos 143). En primer lugar, es una cita parcial del primer fragmento. En segundo lugar, es una alusión a un fragmento de la página anterior que también menciona a los mosquitos, y a otro fragmento de la página antes de ella y así sucesivamente a todos los fragmentos que mencionan mosquitos. De este modo, el penúltimo fragmento tiende hilos de sentido por la novela, pero al mismo tiempo por la combinación arbitraria de sus tres frases pierde todo sentido. Así, la estructura misma de la novela implosiona y el colapso ya es total. 
Mientras la manifestación de lo fantástico en Cortázar parece el centro mismo del cuento cuya estructura no tiembla nunca, en Los ingrávidos se convierte en una herramienta para articular otra poética: una poética que lleva el pasaje a otro nivel y profundiza la ambigüedad hasta poner a la narración misma en crisis.

\section{UN PASAJE HIPERREALISTA}

El pasaje también se deja comprender de otra manera. Luiselli misma caracteriza su novela como hiperrealista (cit. en Barbosa Vera y Scofaulos). Tomando su palabra, propondremos este corriente de las artes plásticas como un nuevo punto de partida.

El realismo moderno, que florece en el siglo XIX con escritores como Stendhal, Ėmile Zola y Honoré de Balzac que convierten "a personas cualesquiera de la vida diaria, en su condicionalidad por las circunstancias históricas de su tiempo, en objetos de representación seria" (Auerbach 522), articula una confianza en la posibilidad de poder representar la realidad en la literatura de una manera adecuada y objetiva. Sin embargo, con el correr de los años, esta confianza desaparece y el realismo queda desacreditado. Décadas después, aproximadamente al mismo tiempo que el posestructuralismo, una nueva corriente realista surge principalmente en EE.UU., el hiperrealismo. Pero como la coincidencia de los dos corrientes indica, su relación con la realidad es más compleja que la del realismo decimonónico.

Para comprender ese retorno al realismo sin una renovación de confianza en la representación, hay que repasar los mecanismos de esta estética. Es lo que hace el crítico de las artes plásticas, Hal Foster, en The Return of the Real (1996). Allí declara que principalmente se ha entendido al realismo de dos maneras opuestas: la imagen como una representación de un referente del mundo real o la imagen como un simulacro que solo se refiere a otras imágenes. Sin embargo, ninguna de las dos llega a comprender la índole del arte pop ni del hiperrealismo que surge de la oposición entre ellas. En cambio, Foster propone una tercera manera: el realismo traumático. Apoyándose en el psicoanálisis de Lacan, Foster entiende lo traumático como "a missed encounter with the real" (132) y manifiesta que "as missed, the real cannot be represented; it can only be repeated, indeed it must be repeated" (132, cursivas originales). Esta repetición no es solo una reproducción entendida como una representación de un referente o una simulación de otra imagen, 
en cambio, es una manera de poner en escena lo real y señalarlo a través de un quiebre de la imagen en un punto que toca al espectador. Refriéndose al punctum de Roland Barthes, Foster plantea que el quiebre se ubica más en el sujeto -entre su percepción y su conciencia-que en el mundo. Es como el punctum que "sale de la escena como una flecha y viene a punzarme" (Barthes, La cámara lúcida 58); "lo que añado a la foto y que sin embargo está en ella" (Ibíd. 94, cursivas originales). De este modo, el quiebre contiene una confusión profunda del sujeto y el mundo, del adentro y el afuera, y es posiblemente de allí que lo traumático del realismo surja ${ }^{12}$.

El hiperrealismo articula, según Foster, esta dinámica: quiere repetir la realidad, pero la realidad de la apariencia y con un ilusionismo extremo intenta sellarla debajo de una acumulación abrumadora de superficies. Sin embargo, no lo logra. Lo real vuelve en un punto de quiebre donde desbarata esta superficie hiperrealista. Un ejemplo, que Foster destaca, es Richard Estes, un pionero del fotorrealismo. Sus pinturas son generalmente cityscapes casi inanimados y marcados por la presencia de superficies brillantes y reflejos -tanto que para Foster representan la realidad como "a visual conundrum" (142, cursivas originales). Una de las más conocidas, Double Self-Portrait (1967), muestra desde afuera una cantina con fachada de ventanales grandes y en ellos el reflejo clarísimo de la calle, en la cual el artista está con su cámara. El trabajo con la apariencia y las superficies es evidente: cada detalle casi se ve mejor que en la realidad y los reflejos son tan claros que se vuelve imposible distinguir afuera de adentro. Como espectador incluso uno se cuestiona si no se han intensificado los reflejos para lograr esta confusión que parece volver lo real inaccesible. Sin embargo, el punctum de Double Self-Portrait no surge de la confusión entre afuera y adentro de la cantina, sino de la confusión entre afuera y adentro de la pintura. Contemplando la obra, el espectador es llevado a cuestionar qué está delante de él y qué está detrás. Mientras la obra físicamente está delante del espectador, ella misma parece sostener que se extiende más allá de sus límites físicos desdoblando la calle detrás del espectador y ubicando al artista a su lado -o tal vez, al espectador dentro de la pintura. De este modo, aunque hay una brecha profunda entre la creación y

12 Barthes localiza, primero, el punctum en un detalle (La cámara lúcida 79) y, segundo, en el noema de la foto, en el "esto-ha-sido" (Ibíd. 146). Sin embargo, Foster, amparándose en el énfasis personal del estudio de Barthes, propone que el punctum también puede residir en la técnica. 
la contemplación de una obra, mediante la perspectiva y la aparente ubicación del artista al lado del espectador, Double Self-Portrait parece ofrecerle al último una experiencia compartida con el primero. O sea, la obra no solo confunde afuera y adentro, sino que propone un pasaje imposible entre el mundo de la pintura y la realidad. Allí es donde lo real vuelve; se sitúa en la ruptura entre la percepción del espectador y su conciencia.

\section{EL PASAJE EN LOS INGRÁVIDOS II}

En Los ingrávidos se desvelan rasgos de un realismo traumático que repite la realidad en cuanto experiencia. Para los personajes, la relación entre ficción y realidad es dinámica. En el punto de inflexión de la novela, cuando la perspectiva cambia de la narradora a Owen, el narrador dice: "La narradora descubre que mientras hilvana un relato, el tejido de su realidad inmediata se desgasta y se quiebra. La fibra de la ficción empieza a modificar la realidad y no viceversa” (Luiselli, Los ingrávidos 62). Así es. La ficción afecta la vida de la narradora tanto a través de la escritura como a través de la lectura. Al escribir acerca de su vida, la literatura se introduce en ella y termina dirigiéndola como cuando su marido hace las valijas para irse solo porque ella lo había escrito (Ibíd. 81) ${ }^{13}$. Con la literatura que lee, pasa lo mismo. Es después de leer Obras de Gilberto Owen que él empieza a invadir la vida de ella. En la azotea de Owen la noche de la primera lectura, la narradora dice: "Fue a partir de entonces que comencé a existir como habitada por otra posible vida que no era la mía, pero que bastaba imaginar para abandonarme en ella por completo" (Ibíd. 32). Pensando en la literatura fantástica es posible leer esta vida como una referencia al fantasma de Owen, pero otra lectura también es posible. Si tenemos en cuenta que se ha destacado la imaginación de la narradora, es posible pensar la vida de Owen como una vida imaginada por la narradora a partir de la lectura ${ }^{14}$.

13 La división entre la escritura y la lectura en Los ingrávidos es levemente arbitraria, dado que parecen inseparables. Por ejemplo, la escritura de la narradora solo afecta su mundo a través de la lectura de su marido.

$14 \quad$ Esta lectura presupone una especie de desarrollo lineal. Por un lado, este se apoya en lo que hemos llamado la aparente lógica narrativa de la novela, según la cual la novela se construye como una doble estructura que se desestabiliza para al final implosionar. Por el otro lado, la misma doble estructura parece contradecir una lectura que de tal manera subordina a 
Antes de seguir, primero hace falta introducir algunas reflexiones de Wolfgang Iser acerca del acto de leer y la relación entre el texto y el lector. Iser enfatiza la participación activa del lector en la producción del sentido del texto literario. En un ensayo temprano, "Indeterminacy and the Reader's Response in Prose Fiction" (1970) declara que el texto literario se caracteriza por "its peculiar halfway position between the external world of objects and the reader's own world of experience" (Iser 8). En cuanto non referencial, el texto literario construye el mundo de la ficción, pero nunca puede producir una imagen completa. Entre la información dada se abren huecos de indeterminación que el lector tiene que llenar construyendo las conexiones necesarias y solo en ese acto de leer, en la interacción compleja entre el texto y el lector, se genera el significado.

En Los ingrávidos se manifiesta una concepción de la literatura análoga. Como una especie de regla de escritura, el narrador propone: "generar una estructura llena de huecos para que siempre sea posible llegar a la página, habitarla" (Luiselli, Los ingrávidos 20). El texto no solo debe permitir al lector pasar por sus salas como uno pasa por un museo sin traspasar los límites cuidadosamente marcados, sino venir con sus cosas, valijas y muebles, a habitarlas. Esto se ve casi literalmente en la forma si se entienden los huecos mencionados como los espacios blancos entre los fragmentos. De este modo, el ideal del lector activo no solo queda como regla de escritura, sino que se propone como uno de los fundamentos de la forma de la novela misma.

Leyendo la novela así, Los ingrávidos parece un relato de la experiencia con la ficción de la narradora. Su compromiso con la lectura y la escritura resulta en una relación tan activa con la ficción que ésta -en la forma de Owen-termina irrumpiendo en su mundo real e incluso llega a reemplazarlo ${ }^{15}$. Pero ¿qué tiene que ver con el hiperrealismo?

En la novela hay un anhelo de la realidad y lo real. La narradora intenta confirmar su propia existencia a través de la escritura, porque, como dice: “cuando alguien ha vivido solo durante mucho tiempo, el único modo de

Owen a la narradora, en vez de considerarlos iguales para el funcionamiento de la obra. Esto indica, primero, que hay una tensión estructural fuerte en la novela y, segundo, que la lectura de la novela como la experiencia de la narradora con la ficción solo puede iluminar la obra parcialmente -como tantas otras lecturas.

15 El interés por la experiencia subjetiva se destaca durante toda la novela en el uso extensivo de la primera persona singular que en gran medida limita la narración a la conciencia de los personajes. 
constatar que sigue existiendo es articular las actividades y las cosas en una sintaxis compartible" (Ibíd. 12). Owen intenta hacer lo mismo pesándose obsesivamente todos los días "para ver si el día anterior [se] había muerto" (Ibíd. 65), lo cual uno puede hacer muchas veces en una vida. Es decir, la realidad es tan inaccesible que los personajes necesitan esforzarse continuamente para confirmar su propia existencia. A pesar de sus esfuerzos no saben nunca con seguridad qué es lo real, y el lector tampoco. En vez de representar la realidad, Los ingrávidos la repite en la forma de la experiencia de la narradora con la ficción, y al leer la novela el lector la comparte con ella. Esta repetición no investiga la esencia de las cosas, sino que en cambio parece mantenerse en una especie de superficie de la experiencia donde lo real y lo ficticio se confunden por completo. Así, por un lado, tapa lo real, pero por el otro, mediante la perplejidad que la confusión entre la ficción y la realidad produce en el lector, lo señala quebrando la apariencia.

Recordando a Richard Estes, podemos llevar esta perplejidad a otro nivel. En Los ingrávidos hay un trabajo claro con la autobiografía y autoficción. Tanto la narradora como Owen parecen escribir novelas, al menos parcialmente, autobiográficas, lo cual enfatizan al comentar que hubieran querido empezar o como termina A Moveable Feast de Ernest Hemingway o como empieza The Crack-Up de Scott Fitzgerald, respectivamente (Ibíd. 11 y 63). Sin embargo, Los ingrávidos lleva el juego con la autoficción más allá y parece proponer una conexión entre la narradora y Luiselli. Las dos tienen varios rasgos en común: son mujeres jóvenes, madres, mexicanas, escritoras, han vivido en Nueva York estudiando en Columbia University y han vuelto a México. Con estas coincidencias, la experiencia repetida de la narradora parece desplazarse a Luiselli que termina ocupando el lugar que Richard Estes ocupa en Double Self-Portrait. Por lo tanto, en vez de compartir la experiencia de la narradora, el lector parece compartir la experiencia de Luiselli, lo cual eleva la confusión entre la ficción y la realidad a otro nivel. La ficción ya no se queda dentro de la novela, sino que parece salir de ella introduciéndose en el mundo del lector ${ }^{16}$.

Entonces, el pasaje entre el mundo de la narradora y el mundo de Owen se puede entender como un pasaje entre realidad y ficción que se forma en la superficie de la experiencia repetida. Un pasaje que mediante el juego con

16 Dado que no es necesario para nuestro argumento, no nos extendemos más acerca de la autoficción. Sin embargo, la relación con este género pudiera ser sin duda el punto de partida de otro estudio. 
la autoficción incluso parece salir de la novela e irrumpir en el mundo real del lector ${ }^{17}$.

\section{PASAJES RADICANTES}

En la imagen del pasaje en Los ingrávidos se dan cita dos estéticas muy distintas: la literatura fantástica en su versión latinoamericana y el hiperrealismo; una estética que juega con las limitaciones de la realidad y otra que intenta repetirla obsesivamente. Para comprender este encuentro mejor nos conviene introducir las reflexiones sobre el arte contemporáneo de Nicolas Bourriaud, las cuales, además, nos van a permitir proponer un marco para la lectura de la novela.

El desarrollo del mercado neoliberal, junto con las redes globales de comunicación e información, tienen consecuencias significativas tanto para nuestras vidas cotidianas como para la del arte. En un intento de captar el efecto de la globalización en el arte de hoy, el curador francés, Nicolas Bourriaud, propone el concepto radicante. Bourriaud toma el término de una especie de planta que echa raíces según su avance, y así, se desarrolla en función del suelo al que se adapta ${ }^{18}$. En el arte, la radicancia se articula como una puesta en escena de la marcha de "las propias raíces en contextos y formatos heterogéneos, negándoles la capacidad de definir completamente la identidad" (Bourriaud 22). Es decir, en vez de expresar la tradición de la que vienen, los artistas y obras expresan el recorrido que hacen entre ella y los distintos contextos que atraviesan. En su realización, la estética radicante tiene varias características, pero aquí nos interesa rescatar la focalización intensa en las dimensiones espaciotemporales y, más específicamente, "el cruce de las propiedades respectivas del espacio y del tiempo, que transforma a este último en un territorio" (Ibíd. 89). Allí reside, según Bourriaud, el mayor

17 En Los ingrávidos, los rasgos hiperrealistas son solo rasgos. Si bien algunas obras de esta corriente trabajan con una ruptura con la apariencia de la realidad -e.g., el cambio de escala que vemos en las esculturas de Ron Mueck como Dead Dad, Boy y Mother and Child (Speranza, "Magias parciales" 59)- la realidad todavía parece reconocible para el espectador. En la novela ese ya no parece ser el caso. La doble estructura de los dos narradores intradiegéticos es claramente imposible y así disuelve la imagen reconocible de la realidad.

18 Bourriaud propone el término radicante en oposición tanto al radical, cuya evolución está determinada por su arraigamiento, como al rizoma, que Gilles Delueze y Félix Gauttari definen en Mil Mesetas (1980), cuya red no permite la existencia de un sujeto (Ibíd.: 57-61). 
hecho estético de nuestro tiempo ${ }^{19}$. Este enfoque se expresa, por ejemplo, en el trabajo con el viaje que se ha vuelto omnipresente no solamente como tema, sino, también, como principio de composición, como forma.

El concepto de Bourriaud no fue concebido para la literatura sino para las artes plásticas, cuyos materiales son distintos. Sin embargo, en Atlas portátil de América Latina (2012), Graciela Speranza lo recupera para la literatura. De acuerdo con Bourriaud, la crítica argentina señala los cambios efectuados por la globalización, pero plantea que este proceso se manifiesta en un trabajo acerca del espacio que se encuentra en las artes plásticas y en la literatura. "En la movilidad real o imaginaria, en el viaje o el paseo urbano, en las migraciones voluntarias e involuntarias” (Speranza, Atlas portátil 16), ambas formas artísticas encuentran formas errantes. Ese concepto es muy parecido al de Bourriaud pero está especialmente orientado hacia el arte y la literatura latinoamericanos.

Ahora bien, ¿es la errancia del texto algo particularmente contemporáneo? No necesariamente. Basta pensar en Rayuela (1963) de Julio Cortázar, en el cual el movimiento es clave. Se manifiesta en el viaje del protagonista de París a Buenos Aires, en la estructura que subraya este viaje nombrando las dos partes "Del lado de allá” y "Del lado de acá” y en la lectura misma. En “Tablero de dirección”, el escritor plantea que "este libro es muchos libros, pero sobre todo es dos libros” (Cortázar, Rayuela 7) y propone al lector dos maneras distintas de leerlo. Al indicar que el libro es más de dos, queda claro que el lector mismo puede elegir cómo recorrer el texto que así se mueve y se transforma según sus decisiones. Además, este movimiento -o más bien vaivén- se manifiesta en las afiliaciones de Rayuela que, fiel a todas, une proyectos poéticos inconciliables (Speranza, Fuera de campo 176).

Sin embargo, el hecho de que podamos encontrar obras con características radicantes o errantes en una época anterior no significa que su función estética fuera igual en ésta y que la manifestación en las obras contemporáneas como consecuencia no sea más que una repetición. Siempre se puede hacer un

19 Se puede discutir en qué medida la idea de la transformación de la representación de tiempo y espacio es nueva. Por ejemplo, ya en 1967 en una conferencia, Michel Foucault leyó el texto que después se publicó como "Espacios otros”. Allí plantea que nuestra manera de experimentar el mundo está cambiando de modo tal que el espacio se vuelve más y más significativo en relación con el tiempo. Éste, en cambio, sería "uno de los juegos de repartición posible entre los elementos que se distribuyen en el espacio" (Foucault 15-17). Si bien esto no es directamente una espacialización del tiempo, sí convierte al tiempo en un factor del espacio. 
argumento según el modelo de "Kafka y sus precursores" (1952) de Jorge Luis Borges. Bourriaud y Speranza tampoco plantean que las características sean nuevas, sino que en nuestro momentos histórico caracterizado por la globalización se manifiestan en las obras de toda una corriente de artistas plásticas y escritores. Rayuela hace visible la debilidad inherente en la caracterización estética de una tendencia: los rasgos nunca se manifiestan únicamente en el objeto caracterizado. Entonces, probemos de leer a Luiselli en relación con las reflexiones de los dos críticos.

En este artículo hemos argumentado que un fuerte interés por el espacio y el movimiento se manifiesta en Los ingrávidos. El tiempo empieza a doblarse, dejando atrás la idea de un progreso que solo permite el movimiento dictatorial hacia adelante, y se convierte en otro dimensión del espacio que se puede recorrer, exactamente como declara Bourriaud. Asimismo, el movimiento es clave para la obra. No toma la forma del viaje, como propone el crítico francés, sino la forma del pasaje -al nivel de la forma saltando de un fragmento a otro y al nivel de la trama posibilitando una comunicación con rasgos fantásticos entre la narradora y Owen o un pase hiperreal entre la ficción y la realidad ${ }^{20}$.

Ahora bien, lo que más nos interesa es que Bourriaud propone que los artistas del arte radicante "expresan menos la tradición de la que provienen que el recorrido que hacen entre aquella y los diversos contextos que atraviesan, realizando actos de traducción" (57). En lo concerniente a Los ingrávidos, es una reflexión pertinente. La novela parece una puesta en escena de la marcha de sus raíces: la tradición latinoamericana en el encuentro con la tradición norteamericana. Ninguna de las dos tiene el poder de definir la índole del pasaje o de la obra. Al contrario, la novela se define por el intercambio plástico y eterno entre ellas, lo cual implica que su sentido no se fija nunca. De esta

20 En relación con el pasaje identitario entre la narradora y Owen, es pertinente notar que el juego del doble es una puesta en duda de la unidad de la identidad. Cuestiona si se mantiene fija y estable en un mundo que se abre a mundos y tiempo ajenos o si ella también se abre desestabilizándose. Bourriaud plantea que en nuestro tiempo "sólo podemos desplazarnos por las culturas sin identificarnos con ellas, crear singularidades sin sumergirnos en ellas, surfear en las formas sin penetrarlas" (46). Vista así, la desestabilización de la única identidad en Los ingrávidos se manifiesta como otra característica del arte radicante. Pero no hay que olvidar que el doble es un tema conocido de mucho antes. En la literatura europea principalmente del siglo XIX con obras como Los elixires del diablo (1815) de E.T.A. Hoffmann, La sombra (1847) de H. C. Andersen, El extraño caso del doctor Jekyll y el señor Hyde (1886) de R. L. Stevenson, etcétera. 
manera, en el trabajo con el pasaje en el nivel temático se produce un pasaje al nivel estético, un pasaje de filiación artística, un pasaje radicante.

Esta capacidad de unir elementos heterogéneos sin forzarlos a entrar en una unidad superficialmente homogénea surge principalmente del uso del fragmento. Roland Barthes, quien a lo largo de su obra se ha destacado por el empleo de esta forma, hace varias reflexiones acerca de su índole. En Roland Barthes por Roland Barthes (1975) propone que el ideal del fragmento en sí es la "alta condensación" (105) y que un texto de fragmentos se puede comprender como "piedras sobre el borde de un círculo" (Ibíd. 104) cuyo centro es indefinido o vacío. Él explica esta imagen con una referencia a André Gide quien declara que la incoherencia es preferible a un orden que deforme. Así, según Barthes, una de las ventajas del fragmento es su capacidad de evadir todo cierre del sentido constantemente posibilitando y sugiriendo conexiones nuevas e inesperadas. Esta es su función -o más bien su consecuencia estética- en Los ingrávidos. La construcción a partir de fragmentos elude todo orden cronológico estricto y toda relación fija entre los elementos del texto, al mismo tiempo que posibilita tanto la incoherencia como la contradicción entre ellos. De este modo, el encuentro en una imagen entre la literatura fantástica y el hiperrealismo se vuelve posible.

\section{CONCLUSIÓN}

En Los ingrávidos de Valeria Luiselli, el pasaje es un motivo central que se reitera en los distintos niveles narrativos. En la forma, el pasaje es el salto de un fragmento a otro con todos los cambios que implica de voz, escenario y momento histórico. Con el subte como un modelo propuesto por la obra para la comprensión de ella misma, la conexión entre el espacio físico y el texto se enfatiza, produciendo una espacialización del texto que invita al lector a romper con una lectura necesariamente lineal. En la trama, el pasaje tiene una posición prominente a partir del cruce entre los hilos narrativos, pero su significado es ambivalente y solo se deja iluminar desde perspectivas distintas. A la luz de la literatura fantástica se presenta como un pasaje entre momentos históricos que se estira a un pasaje entre identidades. Sin embargo, aunque las herramientas fantásticas de la novela son pertinentes, asimismo, es evidente que Luiselli las transforma en la construcción de una poética con una ambigüedad aún más fuerte. Por otro lado, a la luz del hiperrealismo, la novela se propone como la repetición de la experiencia de 
lectura de la narradora y el pasaje se explica como el resultado de la relación activa que la mujer mexicana tiene con la ficción. Sin embargo, al trasladar el hiperrealismo a la literatura, Luiselli lo transforma evadiendo el dogma de repetir una realidad reconocible para el lector. Así, en el motivo del pasaje, las afiliaciones distintas se encuentran. Ambas lo alumbran, pero tanto sus explicaciones del pasaje como sus poéticas se oponen entre sí. Son como el blanco y el negro en la imagen del jarrón de Rubin: perspectivas simultáneas y recíprocamente excluyentes. Sin el privilegio de una definición irrebatible, entran en una negociación perpetua que constituye un pasaje radicante.

No obstante, Los ingrávidos no es solo la constitución de un espacio de la narración, sino también la constitución de un territorio literario en el cual Luiselli intenta ubicarse. La literatura fantástica y el arte hiperrealista no son las únicas afiliaciones tratadas en la novela; al contrario, las referencias literarias y culturales abundan. Son tantas, que en las primeras páginas se menciona a Ernest Hemingway, Walt Whitman, Quevedo, Ezra Pound, Roberto Bolaño, William Carlos Williams, Louis Zukofsky, Emily Dickinson, Lars von Trier, Herman Melville y Gilberto Owen, entre otros. Aunque algunas referencias servirían mejor que otras para recorrer la novela, la gran cantidad indica la multiplicidad de coordenadas en relación con las cuales se puede pensar la obra. Si consideramos a la novela como un mapa de fragmentos, las referencias forman los puntos en un mapa alternativo trazado en una diapositiva que se puede sobreponer al primero. Con sus dos dimensiones, los dos mapas le dan al lector la libertad de trazar los pasajes de su manera, conectando los puntos como prefiera, manifestando la libertad de movimiento en la lectura. O más bien, si volvemos al epígrafe y la imagen del librero podríamos entender las referencias como una biblioteca radicante en la cual cada nombre es una voz que puede entrar en diálogo o ser traducida en el encuentro con otras. A través de la construcción y el ordenamiento inexorable de esta biblioteca, Los ingrávidos perpetuamente señala su lugar en el librero, pero al mismo tiempo niega la posibilidad de la existencia de semejante lugar constante. Allí surge la radicancia más explícita de la obra: del movimiento del libro, de los libros, de la biblioteca. 


\section{BIBLIOGRAFÍA}

Amícola, José. “"La noche boca arriba’ como encrucijada literaria”. Revista Iberoamericana. Vol. LXIII, No 180 (1997): 459-466.

Auerbach, Erich. Mímesis. Trad. I. Villanueva y E. Imaz. México D.F.: Fondo de Cultura Económica, 2002.

Barbosa Vera, Ezequiel y Pablo Scofaulos. "Hiperrealismo afantasmado. Entrevista a Valeria Luiselli”. Revista/Tónica. 10 de octubre de 2012. http://revistatonica.com/hiperrealismoafantasmado

Barthes, Roland. La cámara lúcida. Nota sobre fotografía. Trad. Joaquim Sala Sanahuja. Barcelona: Ediciones Paidos Ibérica S. A., 1989.

Roland Barthes por Roland Barthes. Trad. Julieta Sucre. Barcelona: Kairos, 1978.

Benjamin, Walter. Libro de los pasajes. Trad. Luis Fernández Castañeda, Isidro Herrera y Fernando Guerrero. Madrid: Ediciones Akal, 2007.

Bourriaud, Nicolas. Radicante. Trad. Michèle Guillemont. Buenos Aires: Adriana Hidalgo, 2009.

Caillois, Roger. "Prefacio”. Antología del cuento fantástico. Trad. Ricardo l. Zerlarrayán. Buenos Aires: Editorial Sudamericana, 1967. 7-19.

Coleridge, S. T. Biographia Literaria. Volume II. London: Oxford University Press, 1973.

Cortázar, Julio. Final del juego. Buenos Aires: Punto de lectura, 2011.

Bestiario. Buenos Aires: Punto de lectura, 2007.

Rayuela. Buenos Aires: Punto de lectura, 2007.

"Del sentimiento de lo fantástico". La vuelta al día en ochenta mundos I. México: Siglo XXI, 1996.

Fähndrich, Hartmut. "Ibrahim Al-Koni”. Swissworld.org. s.a.http://www.swissworld.org/en/ switzerland/resources/why_switzerland/ibrahim_al_koni/

Foster, Hal. The Return of the Real. The Avant-Garde at the End of the Century. Cambridge: The MIT Press, 1996.

Foucault, Michel. “Espacios otros”. Trad. Marie Lourdes. Versión, estudios de comunicación y política $\mathrm{N}^{\circ} 9$ (1999): 15-26.

Goloboff, Mario. “Una literatura de puentes y pasajes: Julio Cortázar”. Historia crítica de la literatura argentina. Buenos Aires: Emecé, 2004.

Iser, Wolfgang. Prospecting: from Reader Response to Literary Anthropolgy. Meryland: The Johns Hopkins University Press, 1993.

Luiselli, Valeria. Papeles falsos. Madrid: Sexto piso, 2010.

Los ingrávidos. Madrid: Sexto piso, 2011.

La historia de mis dientes. Madrid: Sexto piso, 2013.

Reynolds, Mark. “Valeria Luiselli. Interview”. Untitled Books N 50. Diciembre 2012. http:// untitledbooks.com/blog/2012/07/valeria-luiselli.htm

Sarlo, Beatriz. “Una literatura de pasajes”. Espacios de critica y producción № 14 (1994): 16-18. 
Speranza, Graciela. Atlas portátil de América Latina. Arte y ficciones errantes. Barcelona: Anagrama, 2012.

Fuera de campo. Literatura y arte argentino después de Duchamp. Barcelona: Anagrama, 2006.

“Magias parciales del realismo”. Mil palabras No 2 (2001): 57-64.

Todorov, Tzvetan. Introducción a la literatura fantástica. Trad. Elvio Gandolfo. Buenos Aires: Paidós, 2006. 